International Journal of Current Advanced Research

ISSN: O: 2319-6475, ISSN: P: 2319 - 6505, Impact Factor: SJIF: 5.995

Available Online at www.journalijcar.org

Volume 6; Issue 4; April 2017; Page No. 3405-3411

DOI: http://dx.doi.org/10.24327/ijcar.2017.3411.0283

Research Article

\title{
INFLUENCE OF PIEZOELECTRIC MATERIAL ON CANTILEVER PLATE NATURAL FREQUENCIES
}

\section{Sampath M.V.B., Karthik Sai CH and Jitendra Z}

Department of Mechanical Engineering, SRKIT, Enikepadu, Vijayawada, A.P, India, 521108

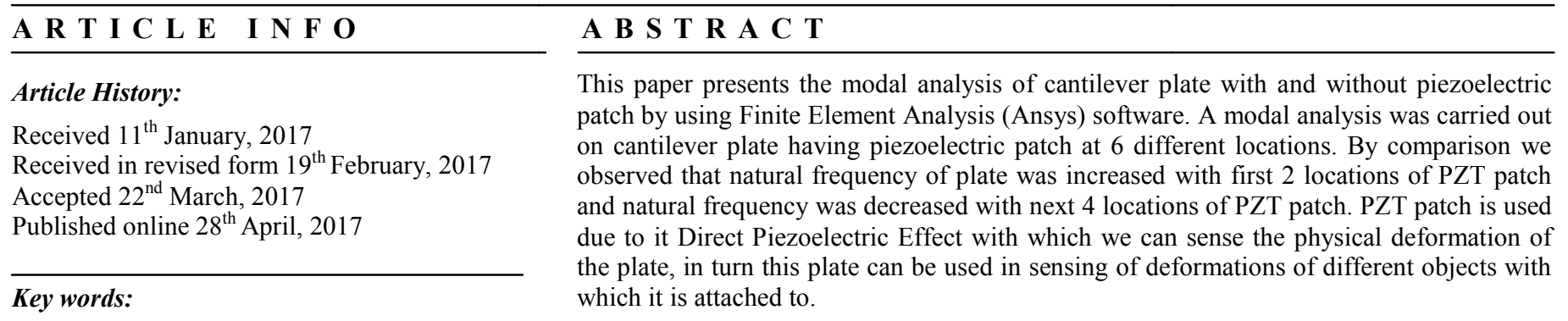

Cantilever plate, piezoelectric patch, Modal

analysis, Natural frequencies.

Copyright $\mathrm{O} 2017$ Sampath M.V.B et al. This is an open access article distributed under the Creative Commons Attribution License, which permits unrestricted use, distribution, and reproduction in any medium, provided the original work is properly cited.

\section{INTRODUCTION}

Piezoelectricity is the ability of a material to develop an electric charge when subjected to a mechanical strain, this effect is called Direct Piezoelectric Effect (DPE) and Conversely material develop mechanical strain in response to an applied electric field, this effect is called Converse Piezoelectric Effect (CPE). Due to this coupled mechanical and electrical properties, piezoelectric materials make them well suited for use as sensors and actuators. Sensors use Direct Piezoelectric Effect (DPE) and actuators use Converse Piezoelectric Effect (CPE). As a sensors, deformations cause by the dynamic host structure produce an electric change resulting in an electric current in the sensing circuit. While as an actuators, a high voltage signal is applied to piezoelectric device which deforms the actuator and transmit mechanical energy to the host structure. Piezoelectric materials basically divided into two group Piezo-ceramics and piezo-polymers. Lead (plumbum) Zirconate Titanate (PZT) became the dominant piezo-electric ceramic material for transducer due to its high coupling coefficient (0.65). When this PZT plate subjected to static or dynamic loads, it can generate voltages as high as 20,000 volts. A steel cantilever plate is considered for the modal analysis coupled with PZT (Lead (Plumbum) Zirconate Titanate) at different positions.

\section{System Model}

A cantilever plate is designed in Ansys with dimensions mentioned below in table.

\section{*Corresponding author: Sampath M.V.B}

Department of Mechanical Engineering, SRKIT, Enikepadu, Vijayawada, A.P, India, 521108
Table 1 Properties of cantilever plate

\begin{tabular}{cc}
\hline Thickness b & $\mathbf{0 . 0 3} \mathbf{~ m}$ \\
\hline Height $\mathrm{h}$ & $0.002 \mathrm{~m}$ \\
Length from fixed end $\mathrm{L}$ & $0.11 \mathrm{~m}$ \\
Young's modulus E & $207 \times 109 \mathrm{~N} / \mathrm{m} 2$ \\
Density $\rho$ & $7800 \mathrm{~kg} / \mathrm{m} 3$ \\
Poisson ratio $\mu$ & 0.3 \\
Density $\rho$ of piezoelectric material & $7800 \mathrm{~kg} / \mathrm{m} 3$ \\
Piezo patch dimensions $\left(1^{*} \mathrm{~b}^{*} \mathrm{~h}\right)$ & $0.02 \mathrm{~m}^{*} 0.01 \mathrm{~m} * 0.002 \mathrm{~m}$ \\
\hline
\end{tabular}

Table 2 Anisotropic Properties

\begin{tabular}{cc}
\hline Linear Elastic Anisotropic properties $\left(\mathbf{N} / \mathbf{m}^{\mathbf{2}}\right)$ \\
\hline D11 & $1.26 * 1011$ \\
D12 & $8.41 * 1010$ \\
D13 & $7.95 * 1010$ \\
D22 & $1.17 * 1011$ \\
D23 & $8.41 * 1010$ \\
D33 & $1.2 * 1011$ \\
D44 & $2.3 * 1010$ \\
D55 & $2.3 * 1010$ \\
D66 & $2.35 * 1010$ \\
\hline
\end{tabular}

Table 3 Electromagnetic Properties

\begin{tabular}{cc}
\hline \multicolumn{2}{c}{ Electromagnetic Relative Permittivity(F/m) } \\
\hline$\epsilon_{11}$ & $1.151^{*} 10^{-3}$ \\
$\epsilon_{22}$ & $1.043^{*} 10^{-3}$ \\
$\epsilon_{33}$ & $1.151 * 10^{-3}$ \\
\hline
\end{tabular}

Table 4 Piezoelectric Properties

\begin{tabular}{cc}
\hline Piezoelectric constant stress & matrix $\left(\mathbf{C} / \mathbf{m}^{2}\right)$ \\
\hline $\mathrm{e}_{12}$ & -5.4 \\
$\mathrm{e}_{22}$ & 15.8 \\
$\mathrm{e}_{32}$ & -5.4 \\
$\mathrm{e}_{41}$ & 12.3 \\
$\mathrm{e}_{53}$ & 12.3 \\
\hline
\end{tabular}




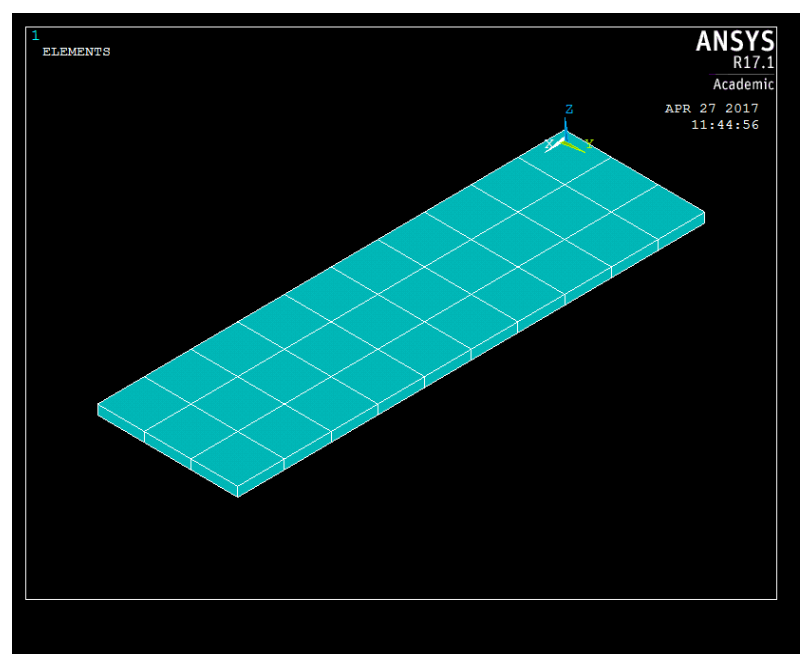

Fig 1 Cantilever Plate without PZT patches.

In ANSYS, the plate is modelled using a solid186 element and the PZT's are modelled using a 3-D coupled element (SOLID226). The actuator is placed in six different positions as shown in Fig [2.2- 2.7]. Note that each square is $0.01 \mathrm{x}$ $0.01 \mathrm{~m}$ in size.

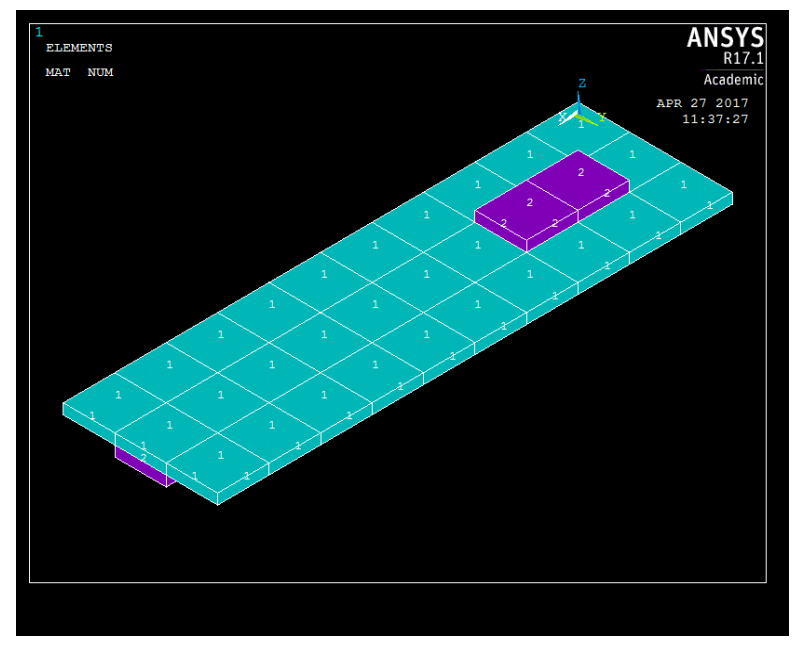

Fig 2 Cantilever Plate with PZT patches at Position-1

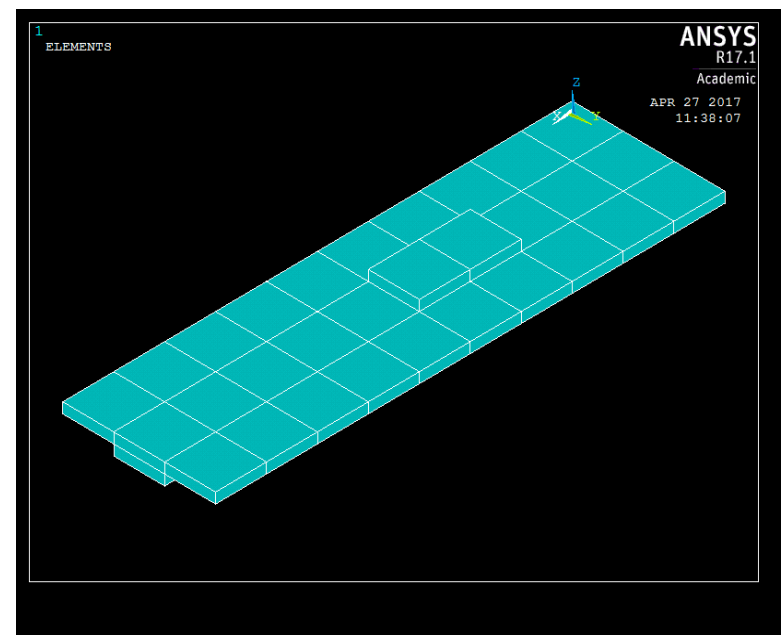

Fig 3 Cantilever Plate with PZT patches at Position-2

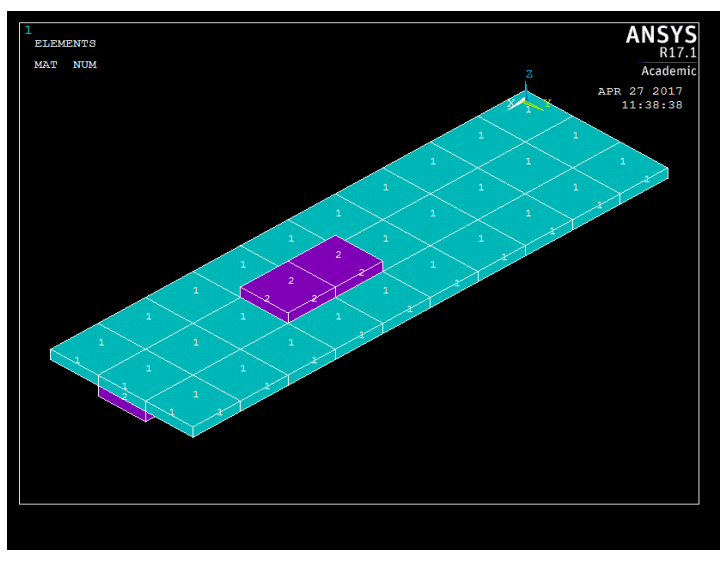

Fig 4 Cantilever Plate with PZT patches at Position-3

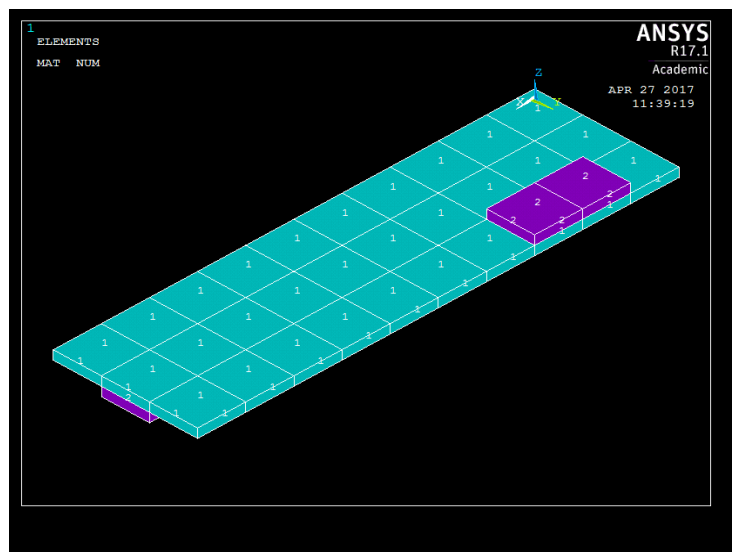

Fig 5 Cantilever Plate with PZT patches at Position-4

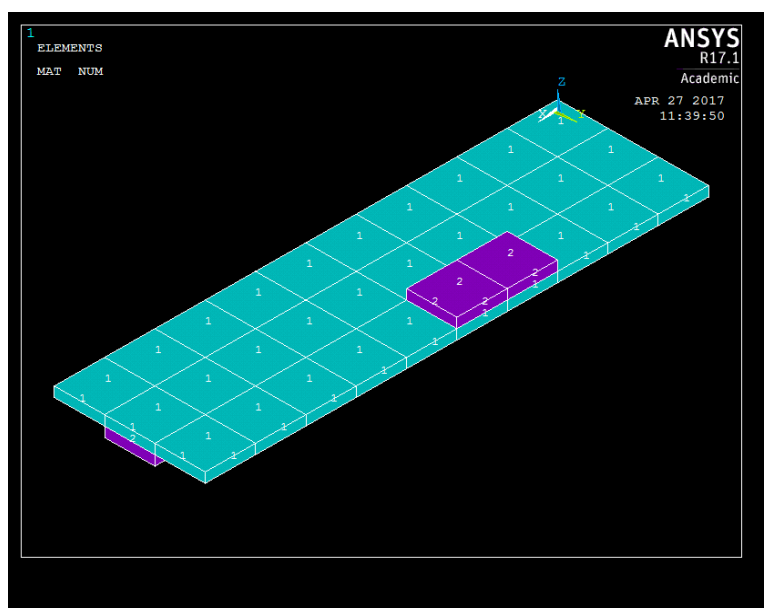

Fig 6 Cantilever Plate with PZT patches at Position-5

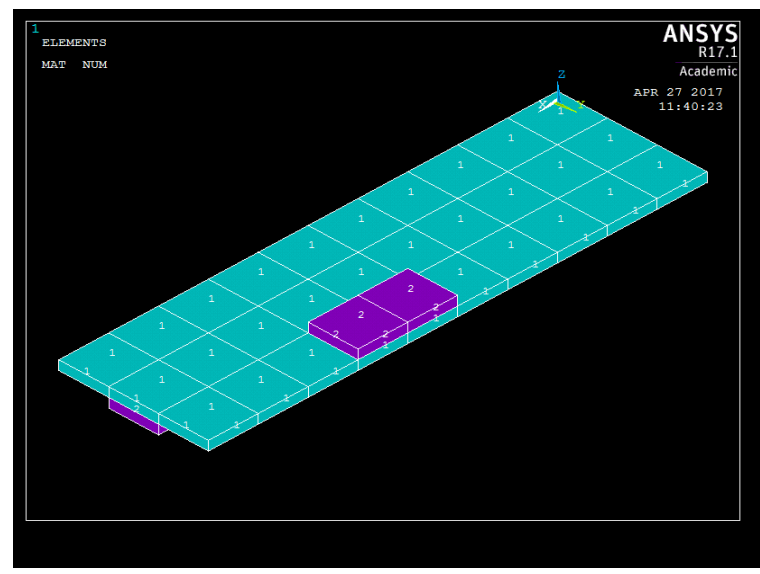

Fig 7 Cantilever Plate with PZT patches at Position-6. 


\section{Previous Work}

Boucher et al developed a perturbation method to numerically determine the Eigen modes of vibration for piezoelectric transducers. The three-dimensional finite element method was formulated to predict the piezoelectric transducer resonance and anti-resonance frequencies as well as sound radiation for different sizes of the PZT cubes. Ha et al modeled laminated composite structures containing distributed piezoelectric ceramic sensors and actuators by finite element analysis. The computer code was developed to analyze the mechanicalelectrical response of the piezoelectric ceramic laminated composites. Experiments were also conducted to verify the computer simulations. The comparisons between predicted and experimental results agreed well. Sun et al derived the frequency response function (FRF) through electric admittance of piezoelectric transducers for obtaining the dynamic parameters of beam structures. However, they did not physically interpret those dynamic parameters.

\section{Proposed Methodology}

Cantilever plate was modeled and properties of steel were assigned to that model. Model analysis was done on plane plate. Piezoelectric material was placed on the plate at 6 different positions and model analysis was carried on. Obtained results were compared with each other arrived with a conclusion for the best position of piezoelectric material.

\section{Simulation Results}

Vibration behavior of a cantilever plate simulated in FEA software ANSYS.

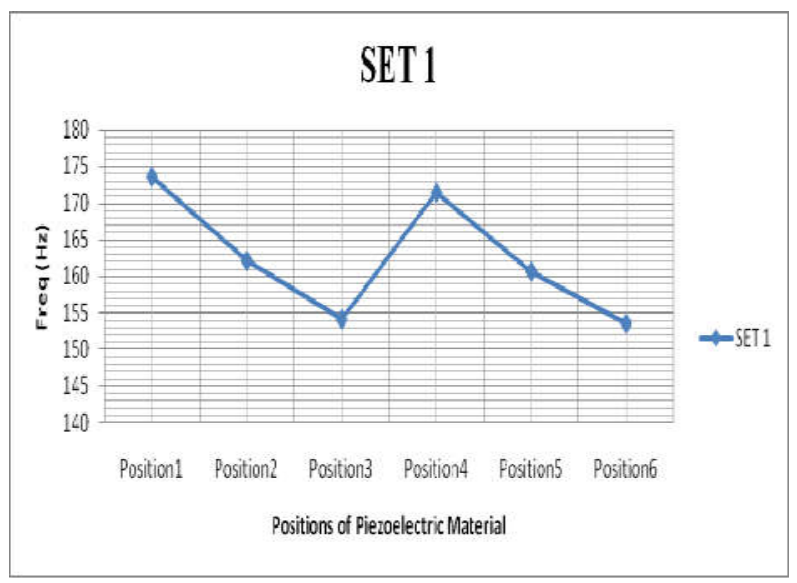

Fig 1 Set 1 Frequencies at different positions.

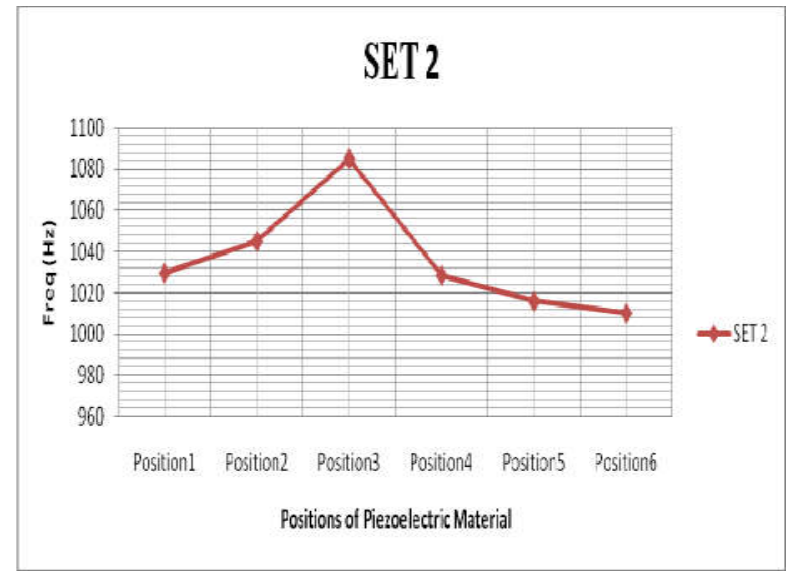

Fig 2 Set 2 Frequencies at different positions.
The natural frequencies are obtained when the PZT patch is placed on cantilever plate at different positions compared to the natural frequencies of the plate without PZT patches as indicated in the figure5.1 to figure5.32.

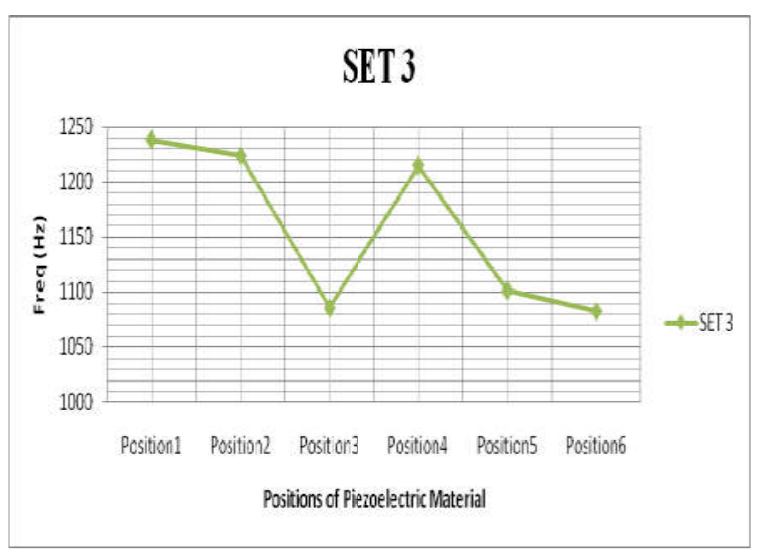

Fig 3 Set 3 Frequencies at different positions

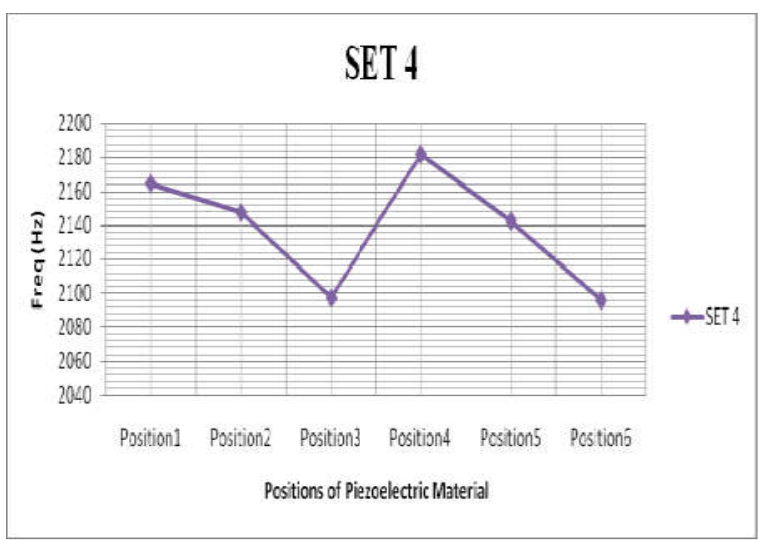

Fig 4 Set 4 Frequencies at different positions

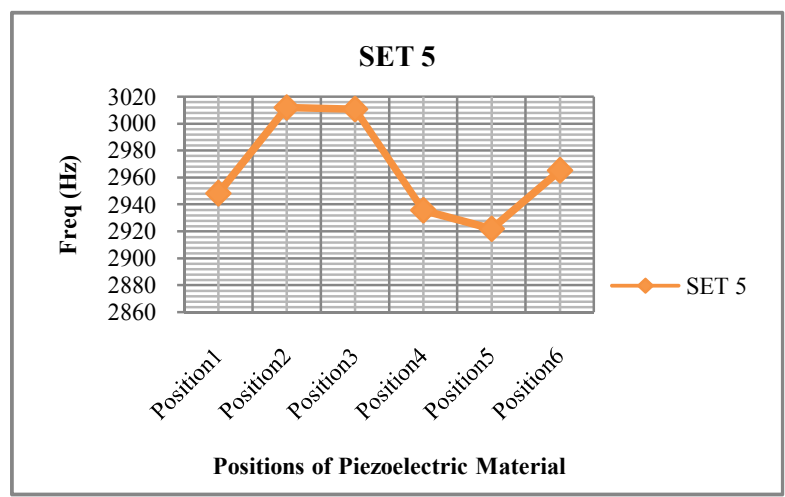

Fig 5 Set 5 Frequencies at different positions

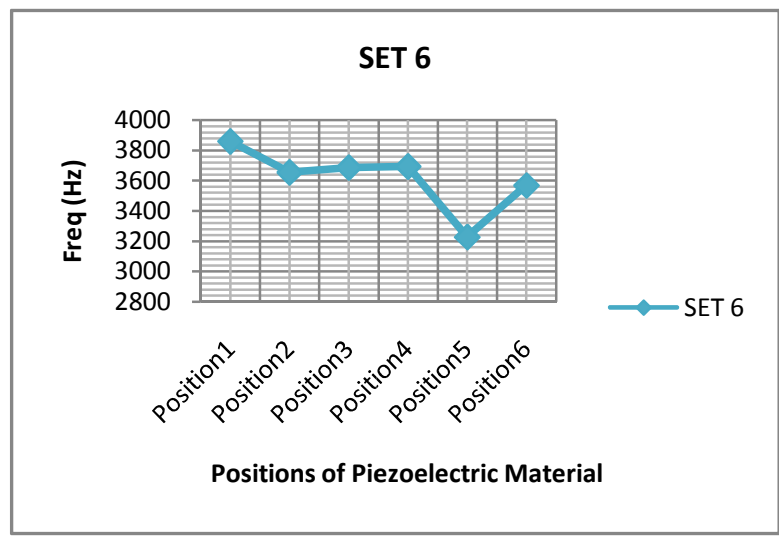

Fig 6 Set 6 Frequencies at different positions. 


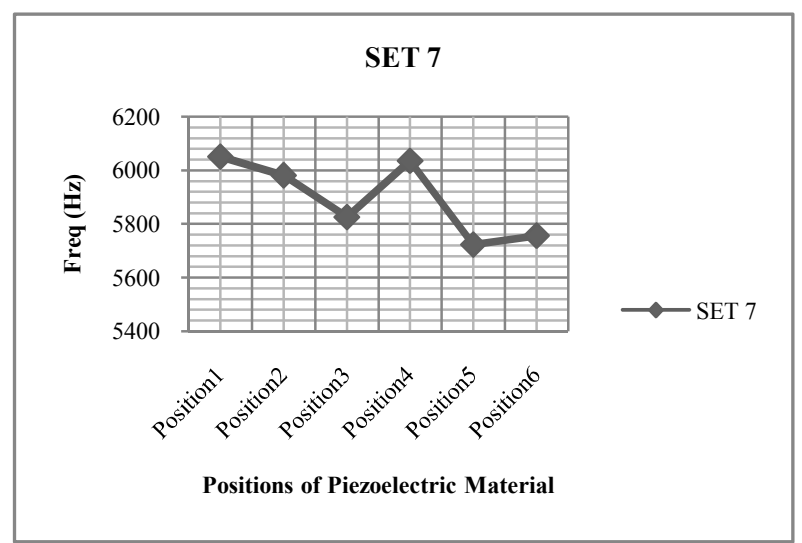

Fig 7 Set 7 Frequencies at different positions

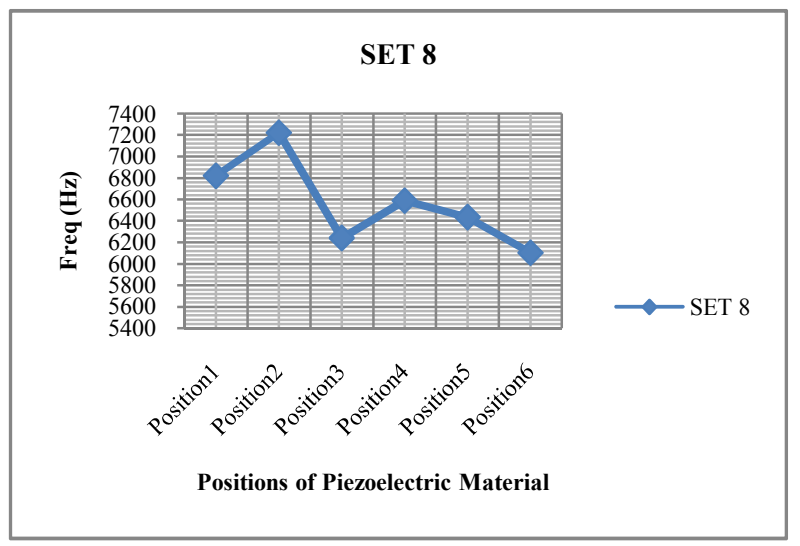

Fig 8 Set 8 Frequencies at different positions

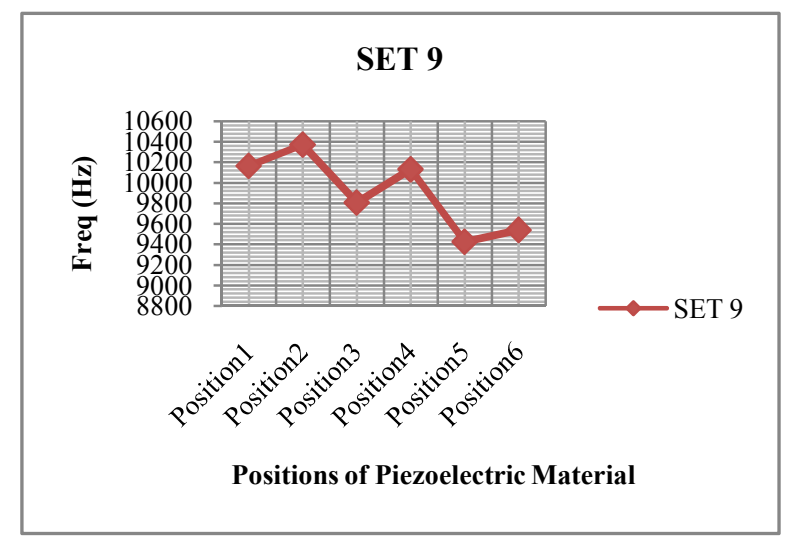

Fig 9 Set 9 Frequencies at different positions

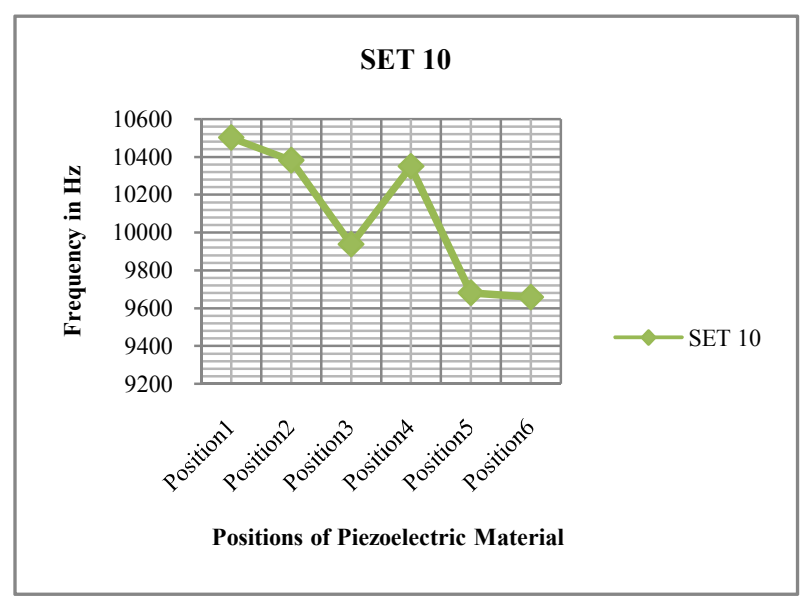

Fig 10 Set 10 Frequencies at different positions.

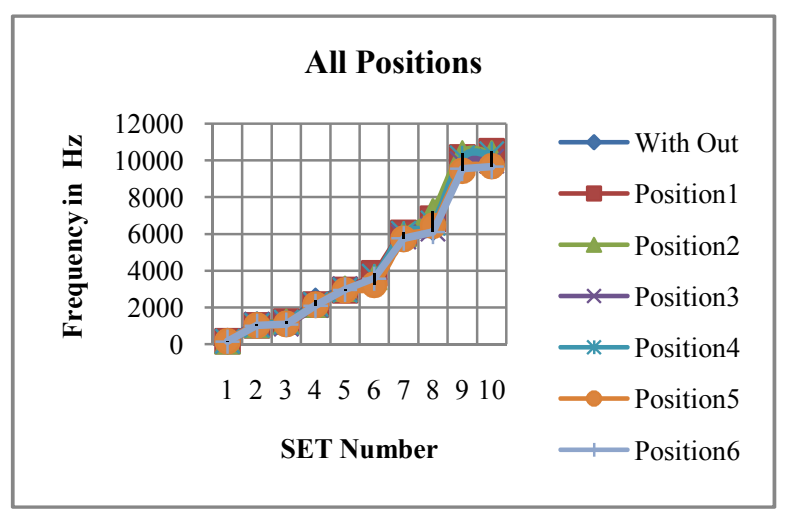

Fig 11 Sets Vs Positions

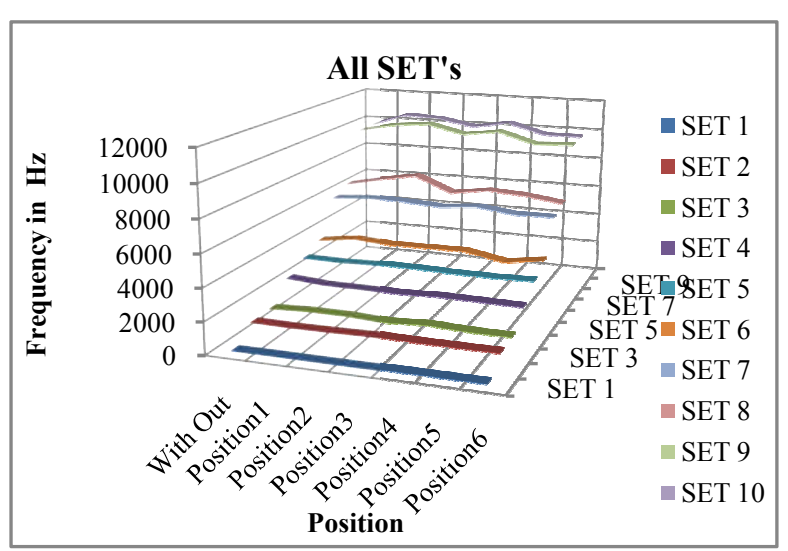

Fig 12 Sets Vs Positions in 3D

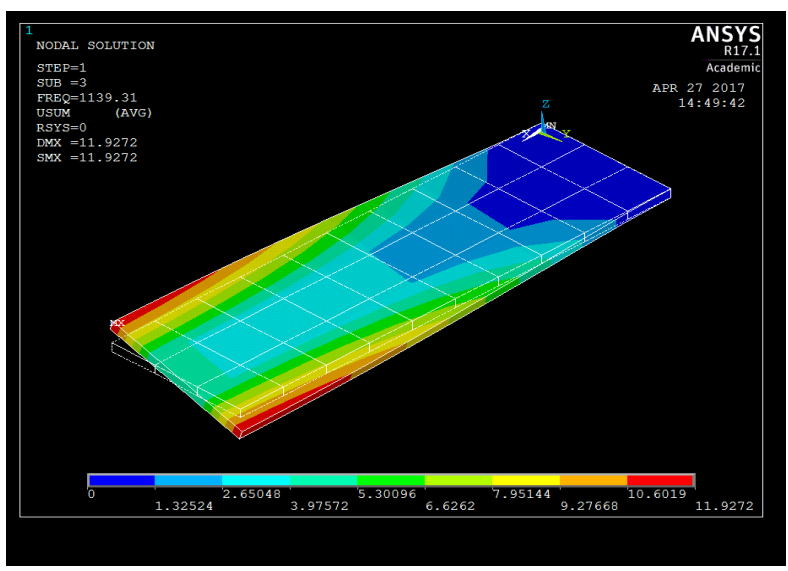

Fig 13 Set 3 Deformation plot of plane plate.

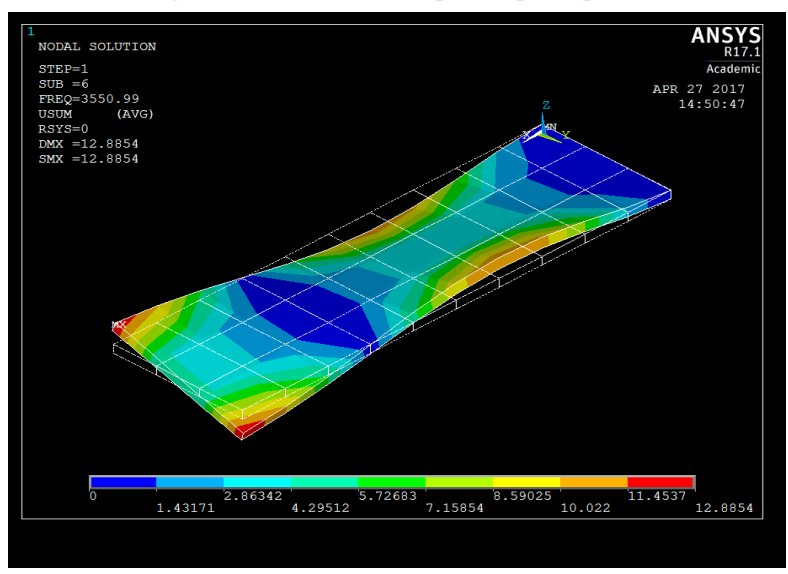

Fig 14 Set 6 Deformation plot of plane plate. 


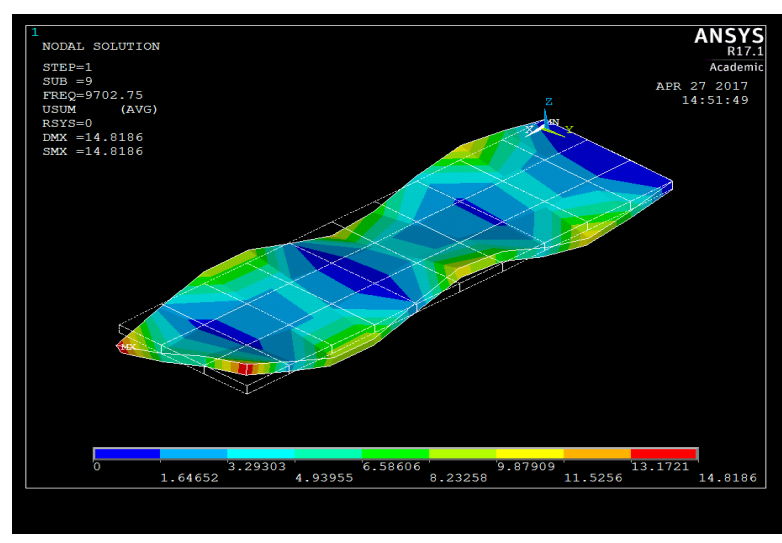

Fig 15 Set 9 Deformation plot of plane plate

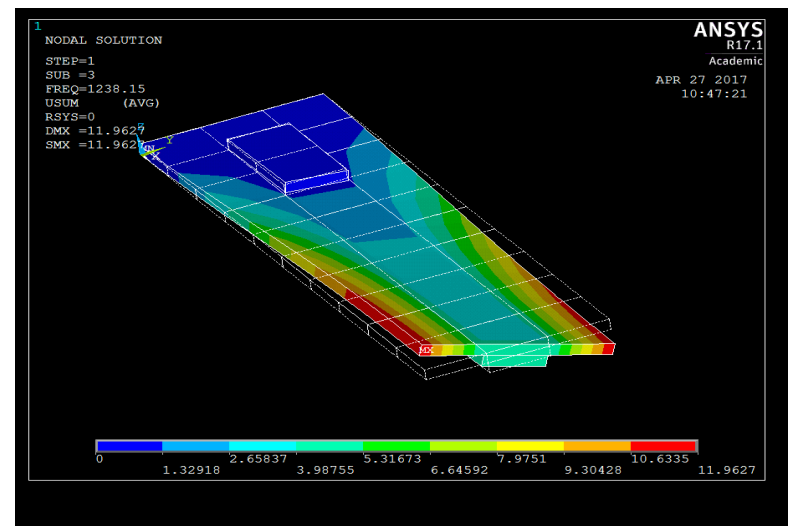

Fig 16 Set 3 Deformation plot of PZT plate at position 1

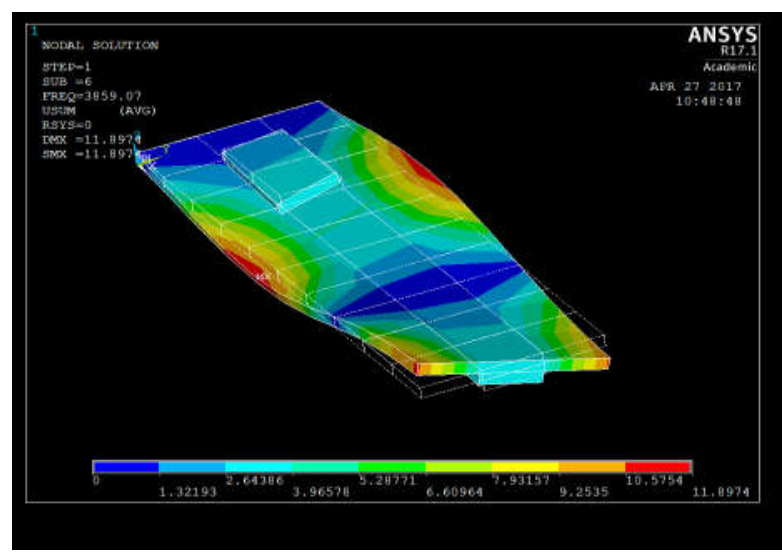

Fig 17 Set 6 Deformation plot of PZT plate at position 1

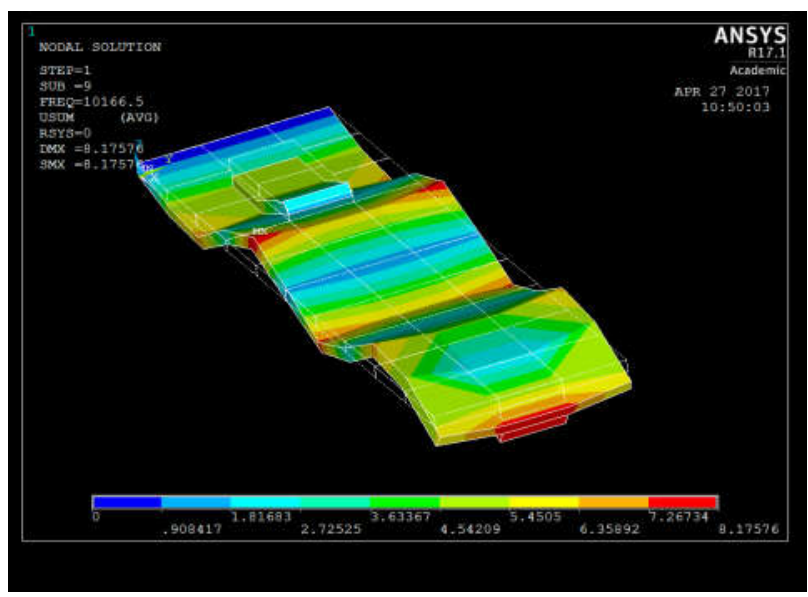

Fig 18 Set 9 Deformation plot of PZT plate at position 1

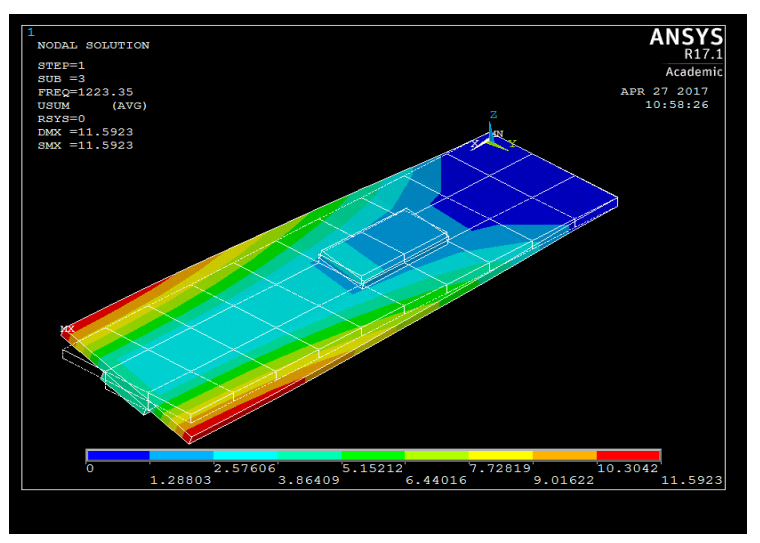

Fig 19 Set 3 Deformation plot of PZT plate at position 2

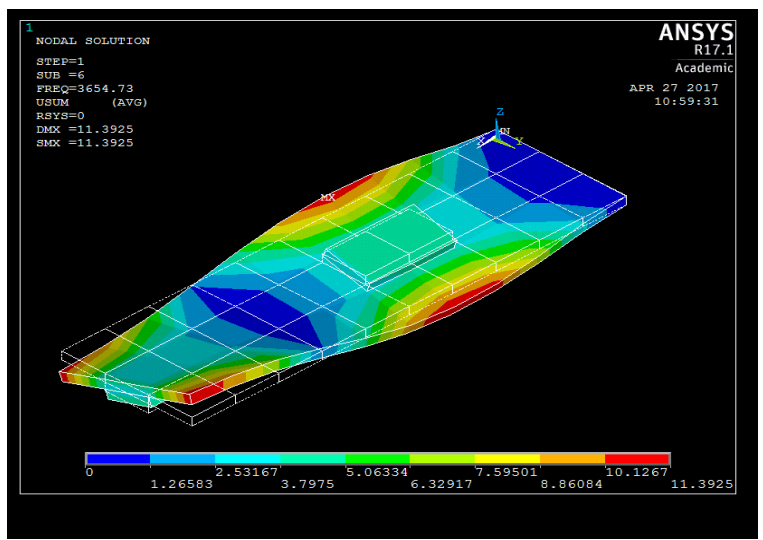

Fig 20 Set 6 Deformation plot of PZT plate at position 2

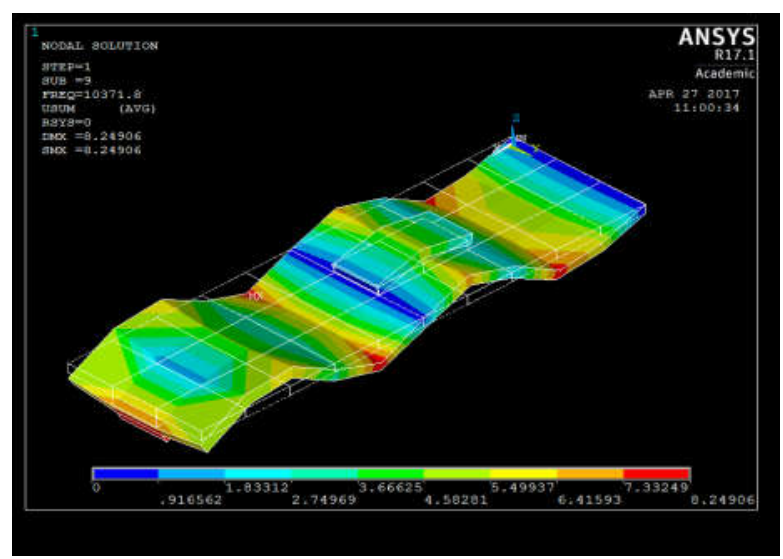

Fig 21 Set 9 Deformation plot of PZT plate at position 2

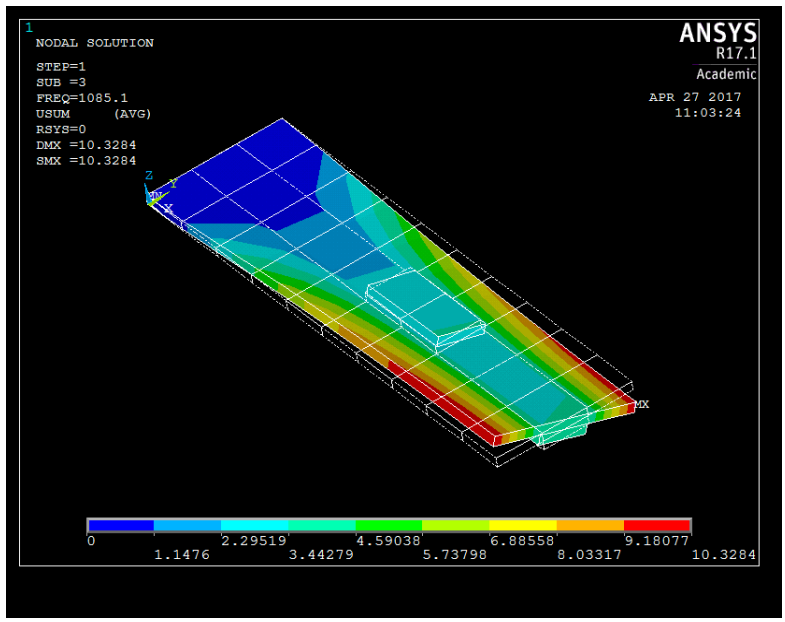

Fig 21 Set 3 Deformation plot of PZT plate at position 3 


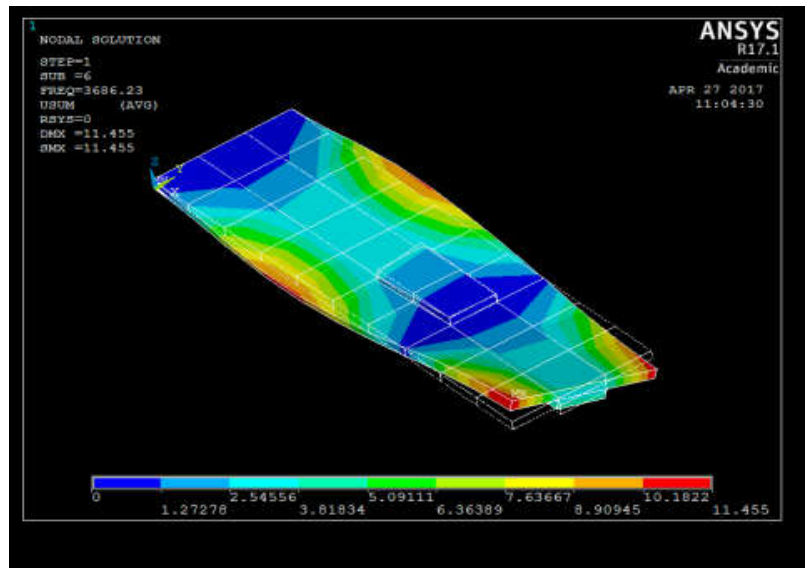

Fig 22 Set 6 Deformation plot of PZT plate at position 3

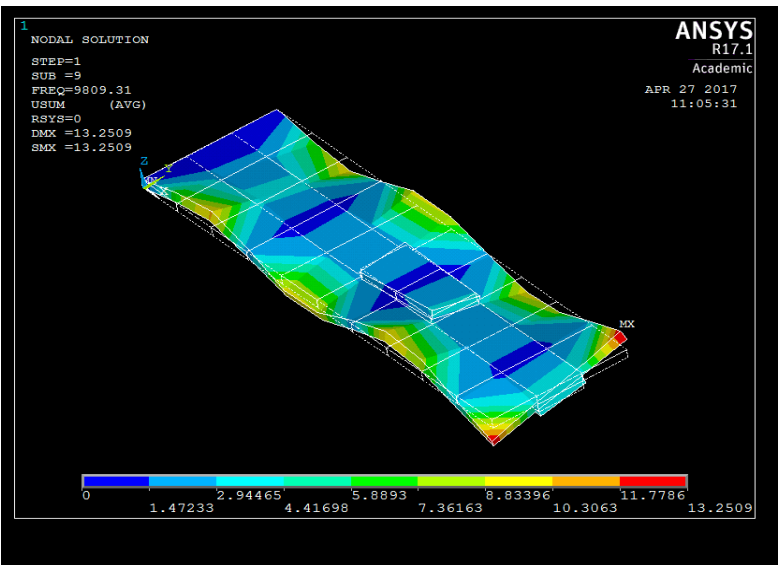

Fig 23 Set 9 Deformation plot of PZT plate at position 3

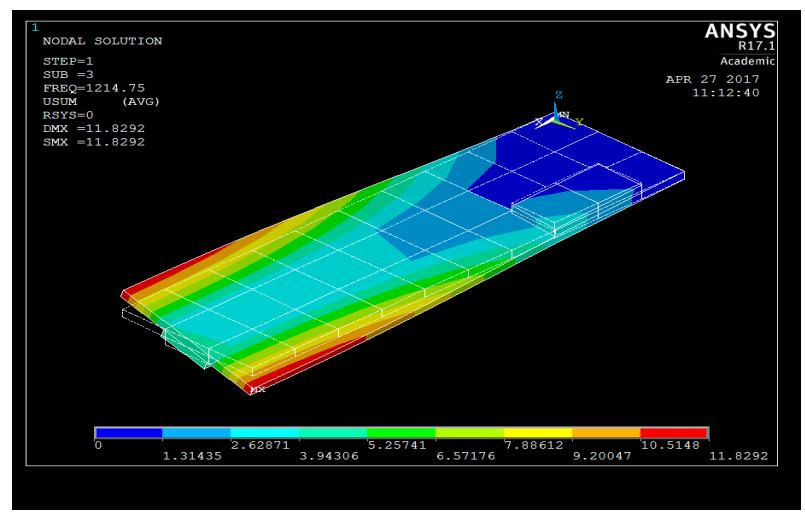

Fig 24 Set 3 Deformation plot of PZT plate at position 4

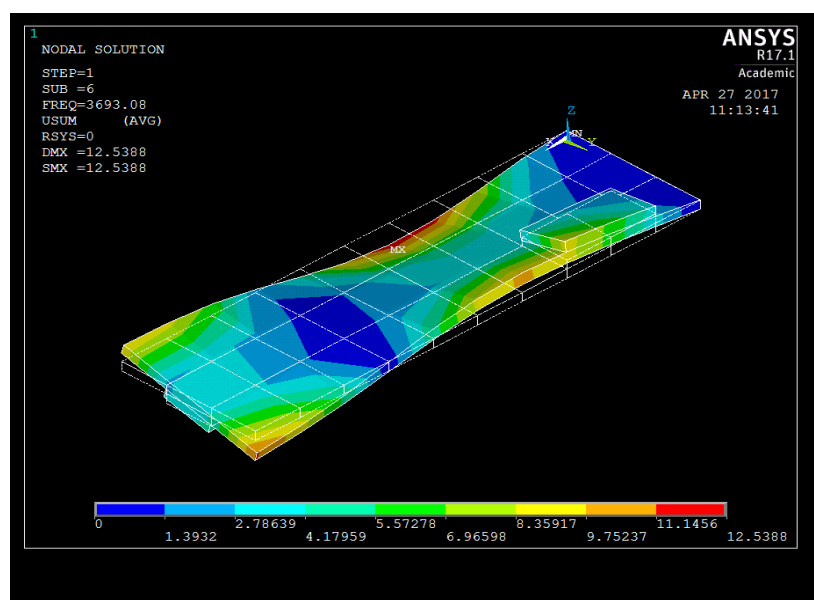

Fig 25 Set 6 Deformation plot of PZT plate at position 4

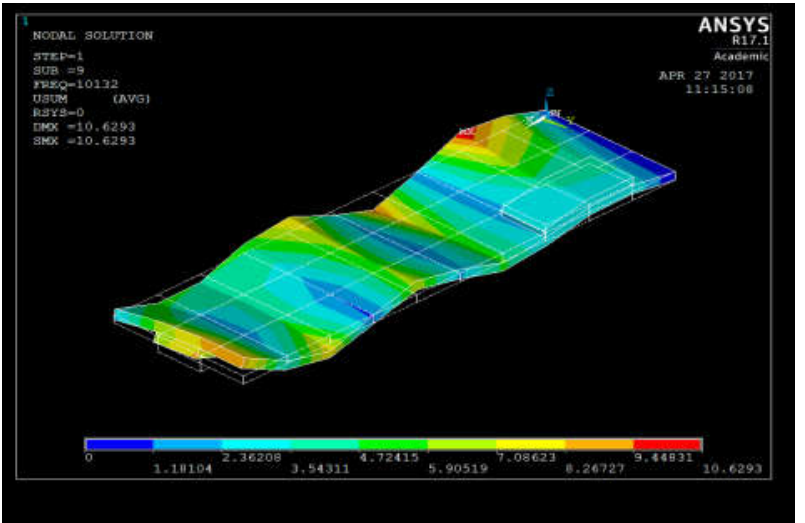

Fig 26 Set 9 Deformation plot of PZT plate at position 4

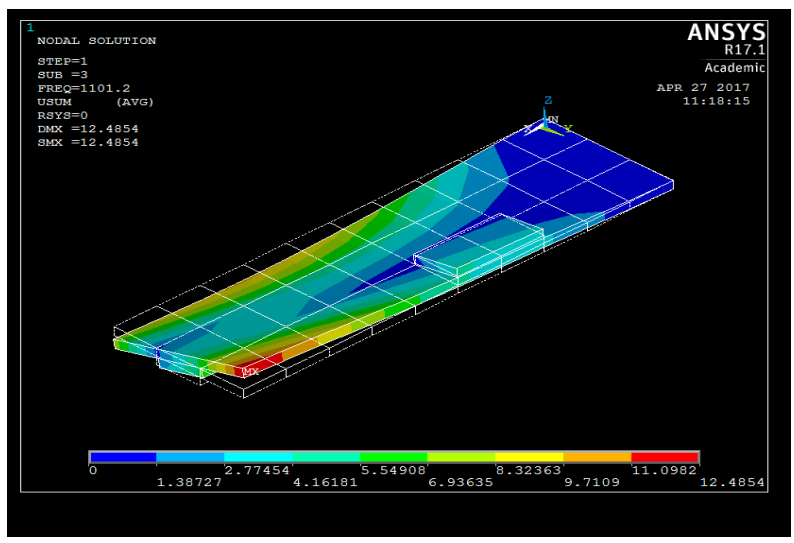

Fig 27 Set 3 Deformation plot of PZT plate at position 5

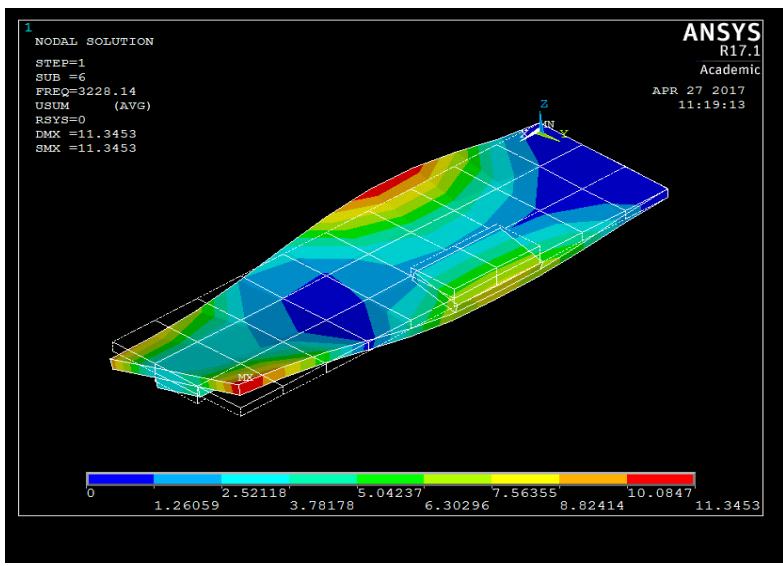

Fig 28 Set 6 Deformation plot of PZT plate at position 5

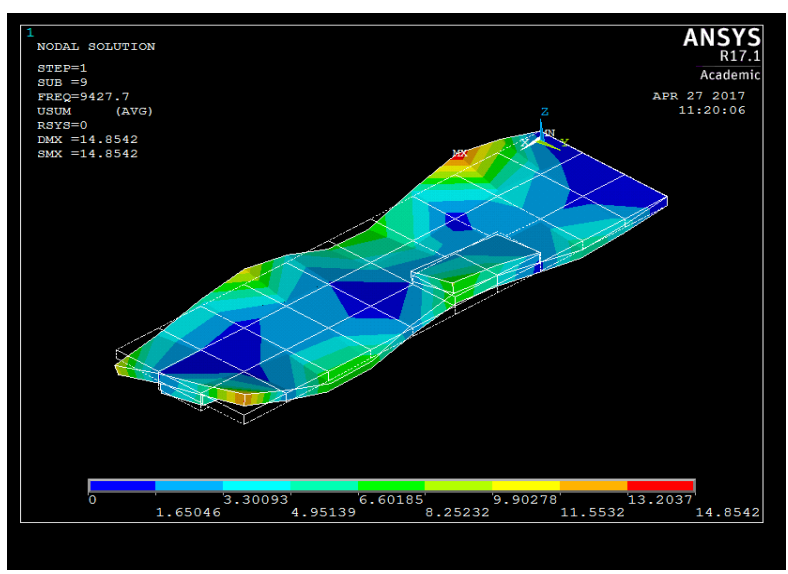

Fig 29 Set 9 Deformation plot of PZT plate at position 5 


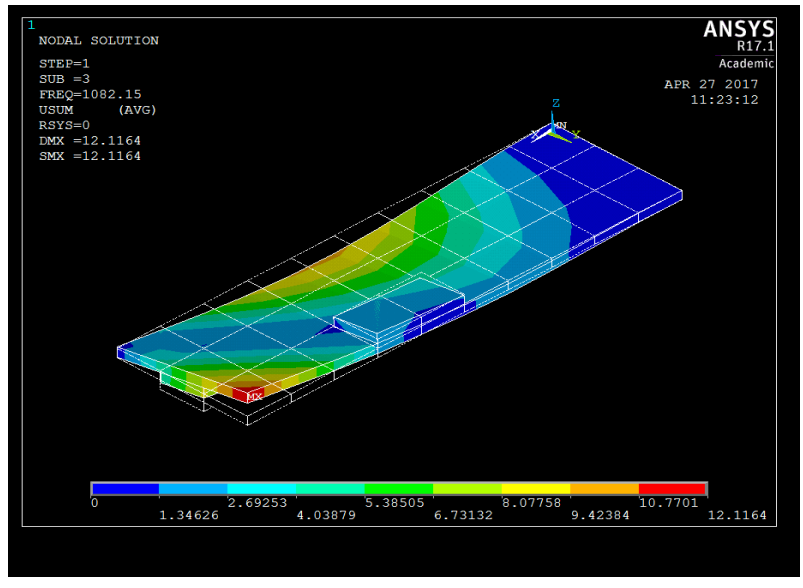

Fig 30 Set 3 Deformation plot of PZT plate at position 6

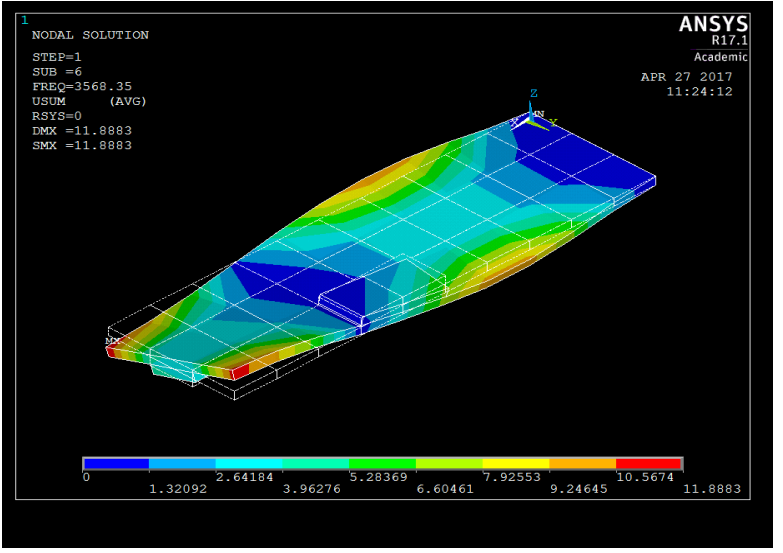

Fig 31 Set 6 Deformation plot of PZT plate at position 6

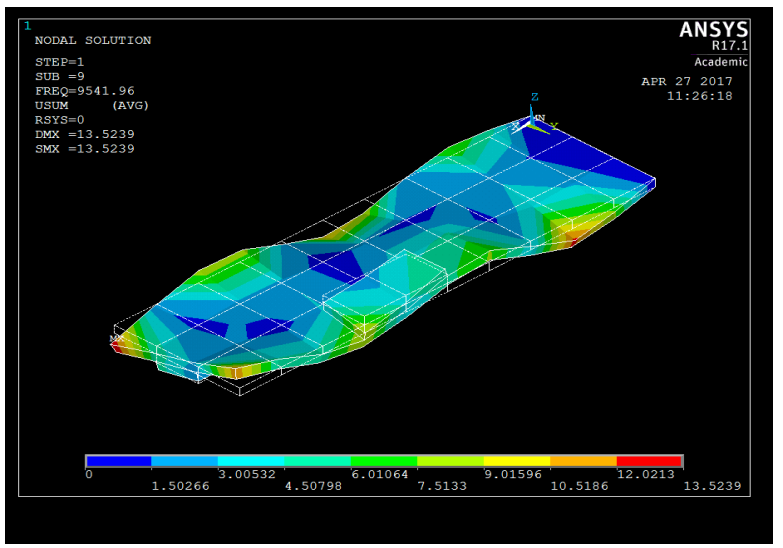

Fig 32 Set 9 Deformation plot of PZT plate at position 6

\begin{tabular}{cccccccc}
\hline S.No & \multirow{2}{*}{ With Out } & Position & Position & Position & Position & Position & Position \\
& & $\mathbf{2}$ & $\mathbf{3}$ & $\mathbf{4}$ & $\mathbf{5}$ & $\mathbf{6}$ \\
\hline $\mathbf{1}$ & 170.99 & 173.54 & 162.08 & 154.06 & 171.38 & 160.6 & 153.49 \\
$\mathbf{2}$ & 1067.6 & 1029.5 & 1044.9 & 1084.9 & 1028.4 & 1015.8 & 1010 \\
$\mathbf{3}$ & 1139.3 & 1238.1 & 1223.4 & 1085.1 & 1214.7 & 1101.2 & 1082.1 \\
$\mathbf{4}$ & 2352.6 & 2164.4 & 2147.3 & 2097.2 & 2181.6 & 2142.4 & 2095.9 \\
$\mathbf{5}$ & 2992 & 2948.3 & 3011.8 & 3010.7 & 2935.7 & 2922 & 2965.3 \\
$\mathbf{6}$ & 3551 & 3859.1 & 3654.7 & 3686.2 & 3693.1 & 3228.1 & 3568.4 \\
$\mathbf{7}$ & 5873.6 & 6051.3 & 5981.9 & 5825.9 & 6035.8 & 5723.2 & 5756.4 \\
$\mathbf{8}$ & 6338.7 & 6820.3 & 7220.9 & 6240.7 & 6588.6 & 6434.3 & 6103.1 \\
$\mathbf{9}$ & 9702.7 & 10166 & 10372 & 9809.3 & 10132 & 9427.7 & 9542 \\
$\mathbf{1 0}$ & 9718.2 & 10502 & 10382 & 9937.8 & 10350 & 9681.3 & 9658.5 \\
\hline
\end{tabular}

\section{CONCLUSION}

Vibration behavior of the cantilever plate was observed as follows. Frequencies of without and with PZT patch at SET's 1,2 and 3 were close to each other and did not showed any significant change. When we reach SET's 4, 5 and 6 there was slight increase in frequencies. For SET's of 7, 8, 9 and 10 there was a drastic change in frequencies.

Surprisingly for positions 1 and 2 the natural frequency of plate was more when compared to without PZT (plane) plate. For positions of 3, 4, 5 and 6 the natural frequencies were reduced comparatively.

\section{Future Scopes}

In future, the application of PZT actuators for the Composite smart structures can be carried out.

\section{References}

1. Boucher, D., Lagier, M., Maerfeld, C., "Computation of the Vibrational Modes for Piezoelectric Array Transducers Using a Mixed Finite Element Perturbation Method", IEEE Transactions on Sonics and Ultrasonics, Su-28(5), pp. 318-330, 1981.

2. Ha, S. K., Keilers, C., Chang, F. K.,"Finite Element Analysis of Composite Structures Containing Distributed Piezo ceramic Sensors and Actuators", AIAA Journal, 30(3), pp. 772-780, 1992.

3. Sun, F. P., Liang, C., Rogers, C. A.,"Experimental Modal Testing Using Piezo ceramic Patches as Collocated Sensor- Actuators", Proceedings of the 1994 SEM Spring Conference and Exhibits, Baltimore, Maryland, pp. 871-879 1994.

4. Allik, H., Hughes, T. J. R.,"Finite Element Method for Piezoelectric Vibration", International Journal for Numerical Methods in Engineering, 2, pp. 151-157, 1970.

5. Kunkel, H. A., Locke, S., Pikeroen, B.,"Finite-Element Analysis of Vibrational Modes in Piezoelectric Ceramic Disks", IEEE Transactions on Ultrasonics, Ferroelectrics, and Frequency Control, 37(4), pp. 316328, 1990.

6. Kagawa, Y., Yamabuchi, T.,"Finite Element Simulation of a Composite Piezoelectric Ultrasonic Transducer", IEEE Transactions on Sonics and Ultrasonics, Su-26(2), pp. 81-88,1979.

7. Challande, C., "Optimizing Ultrasonic Transducers Based on Piezoelectric Composites Using a FiniteElement Method", IEEE Transducers on Ultrasonics, Ferroelectrics, and Frequency Control, 37(2), pp. 135140, 1990.

8. Tsuchiya, T., Kagawa, Y.,"Finite Element Simulation of Piezoelectric Transducers", IEEE Transducers on Ultrasonics, Ferroelectrics, and Frequency Control, 48(4), pp. 872-878 2001.

9. Norwood, C.,"The Measurement of Natural Frequencies and Mode Shapes of Submerged Cylinders Using PVDF Strip Excitation", Proceedings of InterNoise 95, Newport Beach, CA, pp. 1337-1340, 1995. 